\title{
Concussion Awareness of Sports Physicians
}

\section{Spor Hekimlerinin Konküzyon Farkındalı̆̆ı}

\author{
Oğuz Yüksel ${ }^{1}$, Fatma Akgül², Gamze Üngür³, Merve Demir Benli1 ${ }^{1}$, \\ Birsu Topçugil ${ }^{1}$, Murat Duman ${ }^{4}$
}

${ }_{1}^{1}$ Sports Medicine Department, Faculty of Medicine, Dokuz Eylül University, İmir, Turkey

${ }^{2}$ Children's Emergency Department, Educational and Research Hospital, University of Health Sciences, Van, Turkey

${ }^{3}$ Deparment of Coaching Education, School of Sports Sciences and Technology, Dokuz Eylül University, İmir, Turkey

${ }^{4}$ Department of Child Emergency Care, Faculty of Medicine, Dokuz Eylül University, İzmir, Turkey

0 Yüksel

0000-0003-1834-0444

F Akgül

0000-0002-6503-2279

G Üngür

0000-0002-8024-1976

M Demir Benli

0000-0001-9065-593X

B Topçugil

0000-0002-6296-9760

M Duman

0000-0001-6767-5748

Geliş Tarihi / Date Received:

21.06.2018

Kabul Tarihi / Date Accepted: 12.07.2018

Yayın Tarihi / Published

Online: 22.08.2018

Yazışma Adresi /

Corresponding Author:

Oğuz Yüksel

Dokuz Eylül Üniversitesi Tıp Fakültesi, Spor Hekimliği Anabilim Dalı, İzmir, Turkey

E-mail:oyuksel1@yahoo.com

(C2019 Türkiye Spor Hekimleri Derneği. Tüm hakları saklıdır.

\section{ABSTRACT}

Objectives: The aim of this study was to evaluate concussion awareness of sports medicine doctors.

Materials and Methods: A pen and paper survey about concussion is conducted to sports medicine specialists and residents attending to 16th Turkish National Sports Medicine Congress. Survey was composed of 3 sections. First section was questioning if the participant is a resident or specialist, age, number of concussions managed per year and attendence to a lecture about concussion in the past. Participants were asked to choose concussion symptoms from 15 symptoms given in section two. Third section contained 10 true/false questions.

Results: Forty five participants were included in the study. $53.3 \%$ of the participants had never managed concussion in their practice. $64.4 \%$ of the participants had never attended to a lecture about concussion. Mean symptom score was $9.9 \pm 1.8$ over 15 . The average number of correct answers to true/false questions was $4.31 \pm 1.36$ over 10 .

Conclusion: Concussion education and awareness of sports physicians in Turkey are below the expected. Comprehensive education on concussion should be included in medical school programs and sports medicine residency curriculum.

Keywords: Concussion, sports medicine, survey

öz

Amaç: $\mathrm{Bu}$ çalışmanın amacı, spor hekimlerinin konküzyon farkındalıklarını değerlendirmekti.

Gereç ve Yöntemler: 16. Ulusal Spor Hekimliği Kongresi sırasında kongreye katılan spor hekimliği uzmanlarına ve spor hekimliği asistanlarına konküzyon ile ilgili bir kâğıt-kalem anketi uygulandı. Üç bölümden oluşan anketin birinci bölümünde; katılımcıların yaşı, eğitim durumu, konküzyon değerlendirme sıklığı ve daha önce konküzyon ile ilgili bir etkinliğe katılıp katılmadığı (eğitim veya seminer gibi) sorgulandı. İkinci bölümde, sunulan15 semptomdan konküzyonla ilgili olanların seçilmesi istendi. Üçüncü bölümde, konküzyon ile ilgili verilmiş olan 10 adet ifadenin doğru ya da yanlış olarak değerlendirilmesi istendi.

Bulgular: Toplam 45 katılımcı çalışmaya dahil edildi. Katılımcıların \%53.3'ü hiç konküzyon takip etmiyordu, \%64.4'ü daha önce hiç konküzyonla ilgili bir eğitim etkinliğine katılmamıştı. Katıımcıların 15 semptom üzerinden ortalama doğru semptom skoru $9.9 \pm 1.8$ 
idi. 10 doğru/yanlış sorusuna verilen ortalama doğru cevap sayısı 4.31+1.36 idi.

Sonuç: Türkiye'deki spor hekimlerinin konküzyon ile ilgili eğitimleri ve farkındalıkları beklenenden düşüktür. Konküzyon hakkında detaylı bir program tıp eğitimi ve spor hekimliği uzmanlık eğitimi müredatlarına eklenmelidir.

Anahtar Sözcükler: Konküzyon, spor hekimliği, anket çalışması

Available at: http://journalofsportsmedicine.org and http://dx.doi.org/10.5152/tjsm.2019.112

Cite this article as: Yuksel $\mathrm{O}$, Akgul F, Ungur G, et al. Concussion awareness of sports physicians. Turk J Sports Med. 2019;54(1):17-23.

\section{GİRIŞ}

Konküzyon; biyomekanik kuvvetler sonucu gelişen, beyin fonksiyonlarının, mental durumun ve bilinç düzeyinin akut olarak bozulduğu hafif travmatik bir beyin yaralanmasıdır (1). Nöronların makaslama kuvvetlerine maruz kalmasına neden olan, beynin hızlı rotasyonel akselerasyonu ve deselerasyonu sonucu meydana gelir (1). Kafaya direkt darbe sonucu gelişebildiği gibi yüze, boyna veya vücudun başka bir bölümüne darbe sonrası kafaya iletilen itici kuvvetler sonucu da gelişebilir. Standart görüntüleme yöntemleriyle beyinde yapısal bir yaralanma gösterilemezken, beyin fonksiyonlarında geçici bir bozulma vardır (1). Genellikle hızlı başlangıçlıdır ve kısa sürede düzelir (1). Konküzyon tanısı için klinik semptomlar, fiziksel bulgular, bilișsel bozukluklar, nörodavranışsal değişiklikler ve uyku bozuklukları değerlendirilir. Konküzyon geçirmekte olan sporcularda somatik (baş ağrısı, bulantı, kusma, ışı hassasiyeti, ses hassasiyeti vb.), kognitif (sersemlik hissi, yavaşlama, konsantrasyon güçlügü̈, hatırlama güçlüğü vb.), emosyonel (mutsuzluk, aşırı duygusallık, sinirlilik vb.) ve uyku ile ilgili (normalden az uyumak, normalden fazla uyumak, uykuya dalmada güçlük vb.) semptomlar görülebilir (2). Tanı almayan veya iyi yönetilemeyen konküzyon hastalarında, semptomlar iki haftadan uzun sürebilir ve bazen bulguların aylarca devam ettiği postkonküzyon sendromu gelişebilir, hatta bu hastalar ölebilir (3).

Amerika Birleşik Devletleri'nde (ABD) yıllık 1.6 milyon ile 3.8 milyon arasında sporla ilişkili konküzyon yaralanması görülmektedir (4). Amerikan futbolu, buz hokeyi, futbol ve boks en sık konküzyon görülen spor dallarıdır (5). Konküzyon, en sık iki oyuncunun karşılıklı çarpışması sonucu ortaya çıkmaktadır (5). Erkeklerde daha sık görülmekle birlikte, eşit şartlarda yapılan sporlarda kızlarda ortaya çıkma riski daha fazladır (5). Sporcunun konküzyon geçirmesi gelecekte konküzyon geçirme olasılı̆̆ını arttırmaktadır (5). Erişkinlere kıyasla 12-18 yaş arası genç sporcularda kafa travması sonrası konküzyon gelişme riski daha yüksektir ve konküzyon sonrası iyileşme süreci daha uzundur (5).

Konküzyon şüphesi olan sporcular mutlaka oyundan çıkartılmalı ve sporcunun aynı gün oyuna devam etmemesi sağlanmalıdır. Konküzyon yönetiminde temel kural, konküzyon sonrası sporcuların akut semptomlar çözülene kadar fiziksel ve bilişsel olarak dinlendirilmesi, ardından kademeli olarak okula ve spora dönüşünün sağlanmasıdır $(1,6)$.

ABD'de, konküzyonun en sık görüldüğü spor branşı olan Amerikan futbolunun en popüler sporlardan biri olması nedeniyle ve geçmişte yaşanan çeşitli trajik olaylar sonucunda 2009 yılında konküzyon ile ilgili yasal düzenlemeler yapılmıştır. Bu sayede sporcuların, ailelerin ve antrenörlerin konküzyon farkındalığı ve bilgi düzeyi arttırılmıştır (7). Bununla birlikte, sporcularla ilgilenen doktorların da konküzyon bilgisinin çok iyi olması gerekir. Konküzyonla karşılaşma olasılığı yüksek olan branşlarda yapılan anket çalışmalarında ülkeler arasında farklılıklar saptanmıştır. ABD'de pediatristlerin (8), fizyoterapistlerin (9) ve acil tip doktorlarının (10), Kanada'da pediatristlerin (11) ve spor şiropraktörlerinin (12) konküzyon konusunda bilgi düzeyi yüksek iken, Singapur, Sri Lanka ve İrlanda'da acil tıp doktorlarının (13-15) ve İngiltere'de acil tıp asistanlarının (16) konküzyon bilgi düzeyi düşük bulunmuştur.

Sahada ve klinikte, konküzyon geçirmekte olan sporcularin yönetiminde spor hekimlerine önemli bir rol düşmektedir. Konküzyon tanısı ve yönetimi komplikedir ve bazen spor hekiminin 
saniyeler içerisinde konküzyondan şüphelenip tanı koyarak oyuncunun yarışmadan alınıp alınmayacağına karar vermesi gerekir. Sonrasinda da sporcunun tedavisinin yönetiminde ve spora geri dönüş kararının alınmasında spor hekimine önemli bir rol düşmektedir. Dolayısıyla, spor hekimleri konküzyon hakkında çok iyi bilgi sahibi olmalıdır. Ancak, bu konu daha önce hiç araştırılmamıştır. $\mathrm{Bu}$ çalışmanın amacı, Türkiye'deki spor hekimlerinin konküzyon farkındalığını ve bilgi düzeyini araștırmaktır.

\section{MATERYAL VE METOD}

16. Ulusal Spor Hekimliği Kongresi'ne katılan spor hekimliği uzmanları ve spor hekimliği asistanlarına kâğıt-kalem anketi uygulandı.

\section{Anket}

Anket 3 bölümden oluşuyordu. Birinci bölüm, katılımcıların demografik özelliklerine yönelik 4 sorudan oluşmaktaydı; yaş, spor hekimliği uzmanı ya da asistanı olmak, yıllık konküzyon değerlendirme sıklığı, konküzyonla ilgili bir etkinliğe katılım (eğitim, seminer vb.). İkinci bölümde katılımcıların listelenmiș olan 15 semptomdan konküzyonla ilişkili olanları seçmeleri isteniyordu. Bu bölüme verilen doğru cevaplardan semptom skoru elde edildi. Üçüncü bölüm, 10 tane doğru/yanlış sorusundan oluşuyordu. Bu sorulara, 'bilmiyorum' seçeneği eklenerek tahminde bulunulması engellenmeye çalıșıldı. Bu bölüme verilen doğru cevaplardan soru skoru elde edildi. Semptom skoru ve soru skoru toplanarak toplam skor hesapland. Semptom skoru, soru skoru ve toplam skor 100 üzerinden de hesaplandl. İkinci ve üçüncü bölüm "Sporda Konküzyon Konsensüs Bildirgesi" (17) göz önüne alınarak hazırlandı.

Çalışma için Dokuz Eylül Üniversitesi Girişimsel Olmayan Araştırmalar Etik Kurulu'nun onayı alındı.

\section{Ístatistik}

İstatistiksel analizlerde SPSS 22.0 (IBM SPSS Statistics, New York, USA) programı kullanıldı. Araştırmanın tanımlayıcı istatistikleri ortalama \pm standart sapma olarak verildi. Gruplar arasındaki farkı değerlendirmek için Mann Whitney-U testi kullanıldı. Kategorik değişkenler, sayı ve yüzde olarak verildi. İstatistiksel anlamlılık için $\mathrm{p}<0.05$ değeri alındı.

\section{BULGULAR}

16. Ulusal Spor Hekimliği Kongresi'ne katılan 63 spor hekime (43 uzman, 19 asistan) ulaşıldı. Bunlardan 51 tanesi ankete katıldı. Altı anket semptom bölümünün ve/veya doğru/yanlış bölümünün doldurulmamış olması nedeniyle çalışmaya dahil edilmedi. Toplam 45 anket (31 uzman, 14 asistan) çalıșmaya dahil edildi.

Katılımcıların ortalama yaşı $35.3 \pm 8.9$ yıldı. Katılımcıların 24 tanesi (\%53.3) hiç konküzyonla karşılaşmamıştı. Yirmi bir tanesi (\%46.7) bir yılda beşten az konküzyon takibi yapıyordu. Yılda beșten fazla konküzyon takip eden katılımcı bulunmuyordu. Daha önce konküzyon ile ilgili eğitim veya seminer gibi bir etkinliğe katılmış olan doktor sayısı 16 (\%35.6) idi. Yirmi dokuz kişi (\%64.4) konküzyon ile ilgili hiçbir etkinliğe katılmamıştı.

Semptomlara verilen doğru yanıt oranları Tablo 1 'de verilmiştir. Katılımcıların 15 semptom üzerinden ortalama doğru semptom skoru $9.9 \pm 1.8$ idi. Doğru/yanlış sorularına verilen doğru cevap oranları Tablo 2'de verilmiștir. 10 doğru/yanlış sorusuna verilen ortalama doğru cevap sayısı $4.3 \pm 1.4$ idi. Doğru/yanlıș sorularına verilen doğru cevap oranları Tablo 2'de verilmiştir. Toplam skor $14.2 \pm 2.2$ idi. Yüz puan üzerinden değerlendirildiğinde semptom skoru 65.9 , soru skoru 43.1 ve toplam skor 56.8 'e denk geliyordu. Uzmanlar ve asistanlar arasinda semptom skoru, soru skoru ve toplam skor açısından fark yoktu ( $p>0.05)$. Konküzyon ile ilgili bir etkinliğe katılmış olanlarla olmayanlar arasinda semptom skoru, soru skoru ve toplam skor açısından fark saptanmadı ( $p>0.05$ ). 
Tablo 1: Semptomları doğru tanıma sıklığı ve oranları (n (\%))

\begin{tabular}{|c|c|c|c|}
\hline Semptom & $\begin{array}{l}\text { Uzmanlar } \\
\text { (n:31) }\end{array}$ & $\begin{array}{l}\text { Asistanlar } \\
\text { (n:14) }\end{array}$ & $\begin{array}{l}\text { Tüm Katılımcılar } \\
\text { (n:45) }\end{array}$ \\
\hline Üzüntü * & $4(\% 12.9)$ & $4(\% 28.6)$ & $8(\% 17.8)$ \\
\hline Mutluluk & $28(\% 90.3)$ & $14(\% 100)$ & $42(\% 93.3)$ \\
\hline Burun kanaması & $25(\% 80.6)$ & $13(\% 92.9)$ & $38(\% 84.4)$ \\
\hline Solunum sayısı azalması & $22(\% 71)$ & $10(\% 71.4)$ & $32(\% 71.1)$ \\
\hline Bulantı * & $23(\% 74.2)$ & $13(\% 92.9)$ & $36(\% 80)$ \\
\hline Anormal koku duyusu & $21(\% 67.7)$ & $10(\% 71.4)$ & $31(\% 68.9)$ \\
\hline Anormal tat duyusu & $22(\% 71)$ & $10(\% 71.4)$ & $32(\% 71.1)$ \\
\hline Işığa hassasiyet * & $16(\% 51.6)$ & $6(\% 42.9)$ & $23(\% 51.1)$ \\
\hline Sese hassasiyet * & $14(\% 45.2)$ & $6(\% 42.9)$ & $20(\% 44.4)$ \\
\hline Baş ağrısı * & $28(\% 90.3)$ & $14(\% 100)$ & $42(\% 93.3)$ \\
\hline Hatırlama zorluğu * & $30(\% 96.8)$ & $12(\% 85.7)$ & $42(\% 93.3)$ \\
\hline Konsantrasyon zorluğu * & $28(\% 90.3)$ & $13(\% 92.9)$ & $41(\% 91.1)$ \\
\hline Normalden fazla uyuma * & $8(\% 25.8)$ & $7(\% 50)$ & $15(\% 33.3)$ \\
\hline Normalden az uyuma * & $7(\% 22.6)$ & $1(\% 7.1)$ & $8(\% 17.8)$ \\
\hline Unutulan olayları hatırlama & $25(\% 80.6)$ & $12(\% 85.7)$ & $37(\% 82.2)$ \\
\hline
\end{tabular}

Tablo 2: Doğru/yanlış sorularına verilen doğru cevap sayıları ve oranları (n (\%))

\begin{tabular}{|c|c|c|c|}
\hline Doğru/Yanlış Soruları & $\begin{array}{l}\text { Uzman } \\
\text { (n:31) }\end{array}$ & $\begin{array}{l}\text { Asistan } \\
(n: 14)\end{array}$ & $\begin{array}{l}\text { Tüm } \\
\text { Katılımcılar } \\
\text { (n:45) }\end{array}$ \\
\hline $\begin{array}{l}\text { Konküzyon, travma sonrası beyin fonksiyonlarında oluşan geçici } \\
\text { bozulmadır* }\end{array}$ & $30(\% 96.8)$ & $13(\% 92.9)$ & $43(\% 95.6)$ \\
\hline Çoğu konküzyon 7 -10 gün içerisinde iyileşir * & $26(\% 83.9)$ & $6(\% 42.9)$ & $32(\% 71.1)$ \\
\hline $\begin{array}{l}\text { Konküzyon tanısında yardımcı olan görüntüleme yöntemi } \\
\text { Bilgisayarlı Tomografidir }\end{array}$ & $13(\% 41.9)$ & $2(\% 14.3)$ & $15(\% 33.3)$ \\
\hline Geçirilmiş konküzyon ikinci bir konküzyon riskini artırır * & $15(\% 48.4)$ & $5(\% 35.7)$ & $20(\% 44.4)$ \\
\hline $\begin{array}{l}\text { Konküzyon geçirmekte olan sporcunun ikinci bir konküzyon } \\
\text { geçirmesi sporcuyu öldürebilir * }\end{array}$ & $11(\% 35.5)$ & $8(\% 57.1)$ & $19(\% 42.2)$ \\
\hline $\begin{array}{l}\text { Konküzyon geçirmekte olan sporcu için çarpışma riski olmayan } \\
\text { aerobik bir antrenman planlamalıdır }\end{array}$ & $17(\% 54.8)$ & $9(\% 64.3)$ & $26(\% 57.8)$ \\
\hline $\begin{array}{l}\text { Konküzyon geçirmekte olan sporcunun bilgisayar oyunu oynaması } \\
\text { kısıtlanmalıdır* }\end{array}$ & $18(\% 58.1)$ & $6(\% 42.9)$ & $22(\% 48.9)$ \\
\hline Yetişkinler çocuklara göre daha kısa sürede iyileşmektedirler * & $18(\% 58.1)$ & $4(\% 28.6)$ & $22(\% 48.9)$ \\
\hline Kask kullanımı konküzyon riskini azaltmaktadır & $1(\% 3.2)$ & $0(\% 0)$ & $1(\% 2.2)$ \\
\hline $\begin{array}{l}\text { Konküzyon sonrası semptomlar tamamen geçtikten en az } 48 \text { saat } \\
\text { sonra müsabakalı spora dönülebilir }\end{array}$ & $11(\% 35.5)$ & $4(\% 28.6)$ & $15(\% 33.3)$ \\
\hline
\end{tabular}

${ }^{*}$ Doğru olan ifadeler 


\section{TARTIȘMA}

Son yıllarda, özellikle gelişmiş ülkelerde konküzyona giderek artan oranda önem verilmektedir. Konküzyonla karşılaşan hekimlerin yanı sıra sporcuların, antrenörlerin ve toplumun bilgilendirilmesi yönünde çalışmalar yapılmaktadır $(8,11)$. Çalışmamızda katılımcların \%64.4'ü daha önce konküzyon ile ilgili bir eğitim almamış ya da seminer gibi bir etkinliğe katılmamıştı. Benzer şekilde Singapur'daki acil tıp hekimlerinin \%90'ının hiç konküzyon eğitimi almadığı rapor edilmiştir (13). Doktorların konküzyon hakkında bilgili olduğunu bildiren çalışmaların yapıldığı ABD'de ise sporculara bile zorunlu olarak konküzyon eğitimi verilmektedir (7). ABD'de yapılan, 1272 fizyoterapistin katıldığı bir anket çalışmasında katılımcıların \%70'i konküzyonla ilgili resmi bir eğitim aldığını belirtmiştir (9).

Türkiye'de, Mezuniyet Öncesi Tıp Eğitimi Ulusal Çekirdek Eğitim müfredatında "kafa travmaları" konu başlı̆g 1 olarak geçmektedir (18). Ancak kafa travmaları geniş bir başlıktır ve bu konu anlatılırken konküzyondan kısaca bahsediliyor olması muhtemeldir. Ayrica, bu ders acil tip ve beyin cerrahisi gibi branşlar tarafından anlatıldı ̆̆ı için spora bağlı konküzyon olasılıkla daha da kısa anlatılmaktadır. Spor hekimliği uzmanlık eğitim müfredatında konküzyon konu başlığı olarak yer almakla beraber bu müfredat yakın dönemde hazırlanmıştır (19). Spor hekimliği eğiticilerinin mezuniyet öncesi tıp eğitimi derslerinde ve uzmanlık eğitimi sırasında konküzyon konusuna biraz daha ağırlık vermesi yerinde olacaktır.

Bir başka önemli bulgumuz da katılımcıların \%53.3'ünün hiç konküzyon hastası ile karşılaşmamış olmasıydı. Bununla birlikte, hiçbir katılımcı yılda beşten fazla konküzyon takip etmiyordu. Yıllık 1.6 milyon ile 3.8 milyon arasında sporla ilişkili konküzyon gerçekleşen ABD'de nörologların \%10'u hiç konküzyon geçirmekte olan sporcu takip etmediklerini belirtmişlerdir (20). Kanada'daki pediatristlerin \%25'inin hiç konküzyon takip etmediği bildirilmiştir (11). Bununla birlikte Kanada'daki pediatristlerin (11) \%47'sinin, ABD'deki pediatristlerin (8) \%50'sinin ve acil tıp doktorlarının (10) \%88'inin yılda beșten fazla konküzyon takip ettiği rapor edilmiştir.

Türkiye'de spor hekimlerinin konküzyon takip etmemesinin nedenleri; Türkiye'de konküzyon sıklığının az olması, konküzyon geçirmekte olan hastaların spor hekimliği dışındaki branşlara başvuruyor olması ve bu hastalar için spor hekimliği uzmanından konsültasyon istenmiyor olması, hastaların hiç tıbbi yardıma başvurmuyor olması ve/veya daha da önemlisi konküzyon semptomları olan sporculara doğru tanı konamaması olabilir.

Ülkemizde, toplumda ya da sporcularda konküzyon sıklığı ile ilgili bir veri bulunmamaktadır. Yakın tarihli sistematik bir derlemede, 1000 oyun saati bașına Amerikan futbolunda 2.52, futbolda ise 0.44 konküzyon gerçekleştiği bildirilmiştir. Türkiye'de lisanslı futbolcu sayısı 2010 yılında 466.000 olarak bildirilmiştir (21). Diğer spor branşları da göz önüne alınırsa, spora bağlı konküzyon sıklığının az olmadı̆̆ı varsayılabilir.

Konküzyon son yıllarda tıp ve spor camialarında çok dikkat çeken bir konudur. Pubmed'de yapılan "konküzyon" kelimesi aramasında 2008 yılı için 120 makale bulunurken, bu rakam 2017 yılı için 1045’ e yükselmiştir. ABD‘de özellikle Amerikan futbolunda yaşanan trajik konküzyon vakaları nedeniyle 2009 yılından beri Lystedt yasaları yürürlüğe girmiştir. $\mathrm{Bu}$ yasalar antrenörlerin, sporcuların ve ailelerinin konküzyon konusunda eğitilmelerini zorunlu kılmıştır (7). Ülkemizde bu tip bir yasa ya da kural bulunmamaktadır. Çalışmamızın sonuçları da göz önüne alındığında, spor hekimlerinin bile konküzyon farkındalığı yeterince yüksek değilken, sporcuların, teknik ekiplerin ve toplumun konküzyon hakkındaki farkındalığının düşük olduğu varsayılabilir. Konküzyonun akut dönemdeki bulguları (boş bakışlar, sersemlemiş görünüm, sorulara geç yanıt verme, konuşma bozukluğu vb.) çoğunlukla dakikalar içerisinde gerilediği için etkilenenler ya da çevrelerindekiler için bu durum "geldi, geçti" olarak yorumlanıyor ve tıbbi yardım aranmıyor olabilir. Türkiye'de toplumun konküzyon farkındalığını ya da konküzyon sırasındaki tutumunu inceleyen bir çalışma bulunmamaktadır. 
Çalışmamızda katılımcıların 15 semptom üzerinden ortalama doğru semptom skoru $9.9 \pm 1.8$ ve 10 adet doğru/yanlış sorusuna verilen ortalama doğru cevap sayısı $4.3 \pm 1.4$ idi. ABD'de, Rebecca ve arkadaşları 19 doğru/yanlıș sorusu içeren anket çalışmalarının sonucunda pediatristlerin konküzyon hakkında çok bilgili olduklarını bildirmişlerdir (8). York ve arkadaşları, 1272 fizyoterapisti içeren anket çalışmalarında konküzyon bilgisini ölçmek için 15 soru sormuşlardır. Bu çalışmada ortalama doğru sayısı 13.4 bulunmuştur (9). Mitchell ve arkadaşları, acil tıp doktorlarının bilgi seviyesini ölçtükleri anket çalışmasında soruların çok büyük bir oranda doğru bilindiğini bildirmişlerdir (10). Kanada'da yapılan, 809 pediatristin katıldığı bir anket çalışması sonucunda pediatristlerin mevcut konküzyon kılavuzlarına uygun hareket ettiği bulunmuştur (11).

Her ne kadar ABD'de ve Kanada'da yapılan çalışmalarda doktorların konküzyon bilgi düzeyi iyi olarak bildirilse de farklı ülkelerde yapılan çalışmalarda olumsuz sonuçlar da bulunmuştur. Singapur'da yapılan bir çalışmada en sık görülen konküzyon semptomlarını acil hekimlerinin sadece \%46.2'si doğru bilebilmiştir (13). Sri Lanka'da acil tıp doktorlarının sadece \%23'ü konküzyon kılavuzlarından haberdardır (14). Duignan ve arkadaşları, İrlanda'daki acil tıp doktorlarının konküzyon konusunda bilgi eksiklikleri olduğunu (15), Hornby ve arkadașları, İngiltere'deki acil asistanlarının bilgi düzeyinin yetersiz olduğunu bildirmişlerdir (16). Bilgi düzeyine yönelik bu çalışmalardaki sorular standardize olmadığı için ülkeleri birbiri ile karşılaştırmak doğru olmamakla birlikte, Türkiye'deki spor hekimlerinin konküzyon bilgi düzeyinin artırılması gerektiği söylenebilir.

Çalışmamızda bazı soruların doğru cevaplanma oranı çok düşüktü. Kask kullanımının konküzyon riskini azaltmadığını sadece bir (\%7.1) katılımcı bildi. Aynı soruyu, Goonetilleke ve arkadaşlarının çalışmalarında da katılımcıların sadece \%19.3'ü doğru bilirken (14), Rebecca ve arkadaşlarının çalıșmasında katılımcıların \%62'si doğru bilmiștir (8). Kask kullanımının kayakçılarda ve "snowboard"cularda genel kafa travması riskini azalttığı bilinmektedir, ancak bu sporcularda ve
Amerikan futbolu, futbol, ragbi gibi sporlarda konküzyon riskine etkisi belirsizdir (22).

En az doğru yanıt verilen diğer iki soru da konküzyon tanısında görüntüleme yöntemlerinin yeri (\%33.3) ve konküzyon sonrası spora dönüș (\%33.3) ile ilgili olanlardı. Konküzyon beyinde yapısal bir bozulmadan çok fonksiyonel bir bozulmadır. Her ne kadar yeni gelişmiş görüntüleme yöntemleri umut vaat etse de, konküzyon tanısında bilgisayarlı tomografi ve manyetik rezonans görüntüleme gibi standart görüntüleme yöntemlerinin yeri yoktur (23). Yorke ve arkadaşlarının çalışmasında katılımcıların \%71.6'sı ve Mitchell ve arkadaşlarının çalışmasında \%89'u bu bilgiye yönelik soruları doğru bilmişlerdir. Günümüz konküzyon kılavuzlarında, yarışmalı spora dönüş için konküzyon semptomları tamamen geçtikten sonra toplam 7 gün süren kademeli bir rehabilitasyon programı önerilmektedir (1). Yorke ve arkadașlarının çalışmasında katılımcıların \%96.1'i ve Mitchell ve arkadaşlarının çalışmasında \%95'i bu bilgiye yönelik soruları doğru bilmişlerdir.

Katılımcıların semptom değerlendirmesi genel olarak iyiyken, özellikle birkaç semptom daha az sıklıkta doğru olarak bilindi. Bunlar; üzüntü (\%17.8), normalden fazla uyuma (\%17.8) ve normalden az uyuma (\%33.3) idi. Anksiyete, irritabilite, duygusallık ve üzüntü konküzyon değerlendirme araçlarında da geçen konküzyonun emosyonel semptomlarıdır (6). Uyku kalitesi ve/veya süresinde bozulma konküzyonun sık görülen bulgularındandır, hatta sporcuların sağlıklı oldukları dönemde uykularını değerlendirerek olası bir konküzyon yaralanmasında referans olarak kullanılması önerilmektedir (2).

$\mathrm{Bu}$ çalışmanın en önemli kısıtllı̆̆ğı, spor hekimliği doktorlarının hepsine ulaşılamamış olmasıdır. Aynı zamanda çalıșma, konküzyonla karşılașma ihtimali yüksek olan acil tıp, pediatri ve nöroloji gibi diğer branşlardan doktorları içermemektedir.

Sonuç olarak, Türkiye'de spor hekimleri konküzyon ile ilgili yeterli düzeyde eğitim almamaktadır. Spor hekimlerinin konküzyon farkındalığı da yeterli düzeyde değildir. Temel tıp eğitiminde ve spor hekimliği uzmanlık 
eğitiminde konküzyon ile ilgili dersler arttırılmalıdır. Toplumun ve sporcuların konküzyon farkındalığını arttırmaya yönelik çalışmalar yapılmalı, saha düzeyinde ise antrenör ve sağlık ekiplerinin bu konuda eğitim alması gereklidir.

\section{KAYNAKLAR}

1. Mccrory P, Meeuwisse W, Dvorak J, et al. Consensus Statement on Concussion in Sport-The 5th International Conference on Concussion in Sport Held in Berlin, October 2016. Br J Sports Med. 2017;51:83847.

2. Ling H, Hardy J, Zetterberg H. Neurological consequences of traumatic brain injuries in sports. Mol Cell Neurosci. 2015;66:114-22.

3. Nordström A, Nordström P, Ekstrand J. Sports-related concussion increases the risk of subsequent injury by about $50 \%$ in elite male football players. Br J Sports Med. 2014;48(19):1447-50.

4. Guerriero RM, Proctor MR, Mannix R, et al. Epidemiology, trends, assessment and management of sport-related concussion in united states high schools. Curr Opin Pediatr. 2012;24(6):696-701.

5. Harmon KG, Drezner JA, Gammons M, et al. American Medical Society for sports medicine position statement: concussion in sport. Br J Sports Med. 2013;47(1):15-26.

6. Echemendia RJ, Meeuwisse W, Mccrory P, et al. The Sport Concussion Assessment Tool 5th edition (SCAT5): Background and rationale. Br J Sports Med. 2017;51:848-50.

7. Lowrey KM, Morain SR. State Experiences implementing youth sports concussion laws: challenges, successes, and lessons for evaluating impact. J Law Med Ethics. 2014;42:290.

8. Carl RL, Kinsella SB. Pediatricians' knowledge of current sports concussion legislation and guidelines and comfort with sports concussion management: a cross-sectional study. Clin Pediatr. 2014;53(7):689-97.

9. Yorke AM, Littleton S, Alsalaheen BA. Concussion attitudes and beliefs, knowledge, and clinical practice: survey of physical therapists. Phys Ther. 2016;96(7):1018-28.

10. Mitchell SH, Hildenbrand K, Pietz K. Emergency physicians' knowledge of sports-related concussion, referral patterns, and use of return to play guidelines. Athl Train Sports Health Care. 2016;8(5):209-15.

11. Gordon KE, Do MT, Thompson W, et al. Concussion management by paediatricians: a national survey of Canadian paediatricians. Brain Inj. 2014;28(3):311-7.
12. Kazemi M, Bogumil ME, Vora K. Concussion knowledge among sport chiropractic fellows from the Royal College of Chiropractic Sports Sciences (Canada). J Can Chiropr Assoc. 2017;61(3):239.

13. Ong JH, Mfsem F. A Pilot Single-centre cross-sectional study to determine the knowledge and management of sports concussion by emergency physicians: an experience from Singapore. Singapore Med J. 2017;1:17.

14. Goonetilleke C, De Medici A,Kipps C. Knowledge and practice habits of hospital doctors who manage sportsrelated concussion in Sri Lanka. Br J Sports Med. 2017;51(11):53-4.

15. Duignan M, O'connor N, Tillett E, et al. Clinician knowledge and practice habits when evaluating sports related concussion in the emergency department. $\mathrm{Br} \mathrm{J}$ Sports Med. 2017;51(11): 48-9.

16. Hornby C, England M, De Medici A, et al. 55 The recognition of paediatric sports related concussion (516 year olds), initial management and advice among London based emergency medicine trainees. Br J Sports Med. 2017;51(11): 21.

17. Mccrory P, Meeuwisse WH, Aubry M, et al. Consensus statement on concussion in sport-the 4th International Conference on Concussion in Sport held in Zurich, November 2012. Br J Sports Med. 2013;5(4):255-79.

18. Mezuniyet öncesi tıp eğitimi ulusal çekirdek eğitim müfredatı. 2014; Available from: www.yok.gov.tr/documents/10279/38058561/tip_fak ultesi_cep.pdf.

19. Spor hekimliği uzmanlık eğitimi çekirdek müfredatı. 2017; Available from http://www.tuk.saglik.gov.tr/TR,31550/sporhekimligi.html.

20. Conidi FX, Drogan O, Giza CC, et al. Sports neurology topics in neurologic practice A survey of AAN members. Neurol Clin Pract. 2014;4(2):153-60.

21. Lisanslı futbolcu sayısı 466 bine ulaştı. 2010; Available from:

http://www.tff.org/default.aspx?pageID=204\&ftxtID=1 0581.

22. Benson BW, Hamilton GM, Meeuwisse WH, et al. Is protective equipment useful in preventing concussion? A systematic review of the literature. Br J Sports Med. 2009;43(Suppl 1):56-67.

23. Yuh EL, Hawryluk GW, Manley GT. Imaging concussion: a review. Neurosurgery. 2014;75(suppl 4): 50-63.

24. Mihalik JP, Lengas E, Register-Mihalik JK, et al. The effects of sleep quality and sleep quantity on concussion baseline assessment. Clin J Sport Med. 2013;23(5):343-8. 